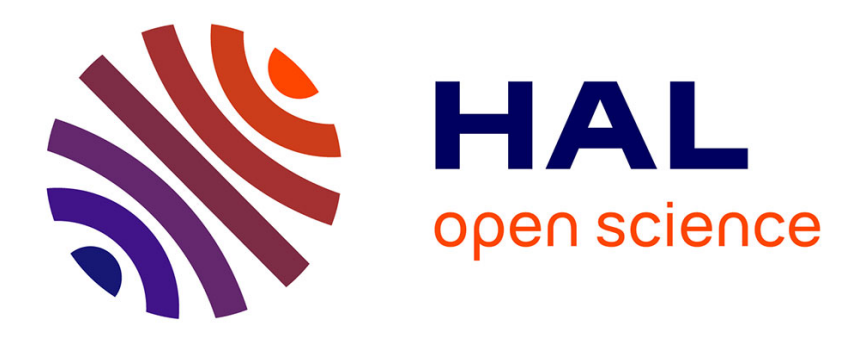

\title{
Neural Correlates of Myths in Which an Image Becomes Alive.
}

Julien d'Huy

\section{To cite this version:}

Julien d'Huy. Neural Correlates of Myths in Which an Image Becomes Alive.. Leonardo, 2013, 46 (2), pp.145-150. halshs-00872502

\section{HAL Id: halshs-00872502 \\ https://shs.hal.science/halshs-00872502}

Submitted on 13 Oct 2013

HAL is a multi-disciplinary open access archive for the deposit and dissemination of scientific research documents, whether they are published or not. The documents may come from teaching and research institutions in France or abroad, or from public or private research centers.
L'archive ouverte pluridisciplinaire HAL, est destinée au dépôt et à la diffusion de documents scientifiques de niveau recherche, publiés ou non, émanant des établissements d'enseignement et de recherche français ou étrangers, des laboratoires publics ou privés. 


\title{
Neural Correlates of Myths in Which an Image Becomes Alive
}

\author{
Julien d'Huy
}

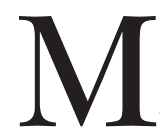

yths and stories in which a 2D or 3D image either becomes alive (or half-alive) or is believed to become alive have been found on every continent, and most of them seem to be very ancient [1]. Moreover, a belief in the danger of such figure animation might explain why dangerous animals in European and Saharan rock art are sometimes painted either with essential parts missing or slashed or pierced with arrows [2] (Figs 1 and 2). Below I attempt to explain the worldwide distribution of this belief and its longevity.

An ill-informed mind could argue that for early humans there would be no reason to draw, sculpt or carve something other than to reflect the original. Capturing motion might have been considered the same as actually reproducing it. Thus the highest compliment conveyed in myth would have been a story line in which an artist's work becomes alive. However, how does this idea explain the universality and persistence of these stories, with the understanding that reflection of an original in art is historically a Western ideal? [3] Australian Aboriginal artists, for instance, chose to mirror not living beings but rather the ancestral beings of Dreamtime, their trails and the result of their actions on the landscape today. However, Aboriginal Australians preserved many stories in which images come to life. The idea, then, that myths of animation are the result of compliments to sculptors or artists is very difficult to sustain.

What, then, is a more likely explanation for the universality of myths or beliefs in which an image becomes or can become alive? The answer may lie partly in the workings of the visual system and the brain that are common to all humans. Specifically, after viewing an image of implied motion, the idea that an image can actually become alive may be more persuasive and persistent in the mind than the idea that it cannot. Consequently, such a mythological pattern may have persisted because the brain, in a specific iconographic context, readily accepts this suggestion.

\section{Neural Correlates of IMPlied Motion}

Many artistic images of human beings can be perceived as a "freeze frame" of an action that involves motion. Generally,

Julien d'Huy (researcher), Centre de Linguistique Anthropologique et Sociololinguistique, Institut Marcel Mauss, École des Hautes Etudes en Sciences Sociales, Paris, France. Email: <dhuy.julien@yahoo.fr>. Web: <http://ehess.academia.edu/JuliendHuy>

See <www.mitpressjournals.org/toc/leon/46/2> for supplemental files associated with this issue. image-makers portray figures in a dynamic balance, with broken symmetry, even instability. Sometimes, they also must reveal to the viewer certain specifics about motion and may use multiple images, affine shear, blur or vector-like lines superimposed on an image [4]. The first step in my argument is based on the activation of motion areas of the brain, a phenomenon called "implied motion," by these images.

Jennifer Freyd has reported on the phenomenon of representational momentum [5]. Pictures that depicted a situation involving motion were briefly shown to observers. After a pause, subjects were shown either the same picture or a picture showing action slightly forward or backward in time in relation to the original image. The observers had to indicate quickly whether the second picture was the same or different from the first. The fact that observers took longer to decide whether the "time-forward" picture was different from the original has been interpreted as indicating a mental "unfreezing" of the picture with implied motion and an anticipation of the forthcoming motion. When implied motion "continues" in a viewer's mind, this is reflected in the activity of the brain.

The middle temporal (hMT+) cortex is a sensitive brain region involved in motion perception. Functional magnetic resonance imaging (fMRI) studies have shown a higher blood oxygen level (or BOLD) in the hMT+ complex in subjects presented with greyscale photographs that implied motion in nature scenes, animals or humans than with similar images that did not imply motion [6]. Moreover, viewers of images of Classical (Fig. 3) and Renaissance sculptures with minor modifications in the proportions to imply motion also showed a significant BOLD increase in the hMT+ complex [7]. If additional proof is needed, EEG scans record an increase of the visually evoked potential in hMT + when subjects view greyscale photographs of humans that imply motion in contrast with greyscale photographs of static humans [8]. This response can be reduced when the subjects are pre-adapted by viewing real motion, strongly indicating that the processing of real and implied motion occurs in at least one common brain area [9]. The occurrence of these responses in the absence of color and with little modification in the proportions of sculptures implies that hMT+ activation may also occur with paintings or drawings. 


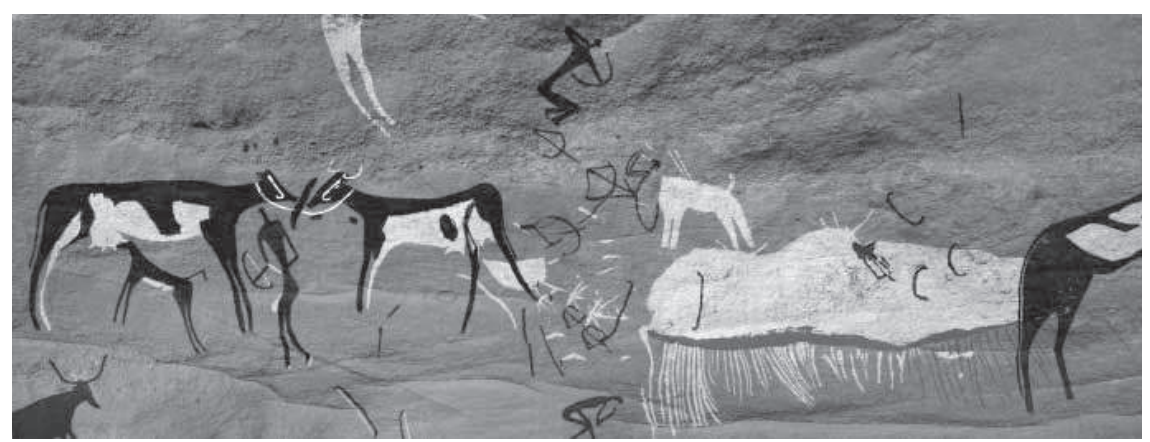

Fig. 1. Mutilated rock painting of a lion, Jebel al-Uweynât Massif, Sahara Desert, ca. 60004000 BCE. (Photo $\odot$ Jean-Loï Le Quellec) Such damage to early images of dangerous animals has been explained by a dread of the animation of these figures.

A recent finding corroborates this hypothesis. Line drawings by Katsushika Hokusai (Fig. 4), a leading artist of the 18th-century Ukiyo-e school, convey a vivid feeling of motion, created by the drawings of bodies in highly unstable positions. The sketches by this artist implying motion, as opposed to images devoid of it, strongly activated the motionsensitive visual cortex (including hMT+ in the human extrastriate cortex) on both sides of the brain [10].

While the hMT+ area of the brain is involved in the perception of both abstract/non-biological and biological motion, a part of the superior temporal sulcus (STS) region (as defined by Allison and et al. [11]) is also activated by implied motion concurrently with hMT+ [12]. A study by Osaka et al. [13] has also indicated that observation of implied motion in a drawing produces increased activity in the right middle temporal gyrus of the STS region. Significantly, STS is activated both in macaque monkeys and in humans at the sight of specific articulated body actions and by the consequent articulated static body postures [14]. (Articulated actions are those in which one body part moves with respect to the remainder of the body, which remains static; articulated static body postures contain a torsion or rotation between parts, while non-articulated postures do not.)

Moreover, it is known that when actions by other individuals are observed, the somatosensory, motor and premotor cortices of the viewer resonate by activating a neural population simulating the perceived actions in a strictly congruent fashion. The activity of mirror neurons may help in predicting another individual's subsequent actions and in inferring intention, may be important for learning new skills by imitation and may contrib- ute to understanding others' mental states [15].

Data also suggest that mirror neurons dedicated to an observed motion respond more strongly to implied motion than do other neurons. The observation of Classical and Renaissance sculptures has been shown to elicit activation of the ventral premotor cortex and the posterior parietal, suggesting motor resonance between the observer and the executor of an action congruent with the implied movements portrayed in the sculptures [16]. Similarly, observation of static phomotion produces greater activation in the primary motor and premotor cortex and supplementary motor area, as well as the posterior parietal cortices, consistent with the mirror properties of cortical motographs of human actions with implied p. 327). tor neurons [17]. Nevertheless, Osaka et al. [18] could not find any mirror-related activation areas involving pre-motor and related areas, except possibly the right cerebellum. Further investigation will be necessary.

Thus, we see that observation of implied motion produces a clearly higher level of activation of brain areas, correlated with the perception of general motion cues $(\mathrm{hMT}+)$ and more specifically biological motion (STS and mirror neurons), than observation of static images without implied motion. I argue below that this unconscious neural anticipation of motion in artistic images becomes conscious in human beings, and thus explains the content of certain myths.

\section{MACAQUE AND HUMAN PERCEPTION AND IMPLIED MOTION}

Many monkeys possess a prototypical motion area in the brain that processes motion implied by inanimate forms. Moreover, when presented with still pictures, they exhibit adaptive responses as if these images could really move. This can be illustrated through the case of the rhesus macaque, which is very close to humans in physiological and evolutionary terms. A sub-population of motionselective cells in the medial and medial superior temporal area of this monkey's brain responds to Glass sequences as if they contained real coherent motion [19]. Additionally, cells in the anterior part of the macaque STS respond to spe-

Fig. 2. Paper tracing over cave painting, Lascaux, Dordogne, France (original painting ca. 15,000 BCE). A dread of figures animation may have been shared by the painters of the Lascaux cave, where images of dangerous animals were notably marked by lines or drawn spears (tracing by André Glory, reprinted from André Leroi-Gourhan, "La Nef et le Diverticule des Félins," in A. Leroi-Gourhan and J. Allain, eds., Lascaux inconnu. XII Supplément à Gallia Préhistoire [Paris: Centre National de la Recherche Scientifique, 1979]

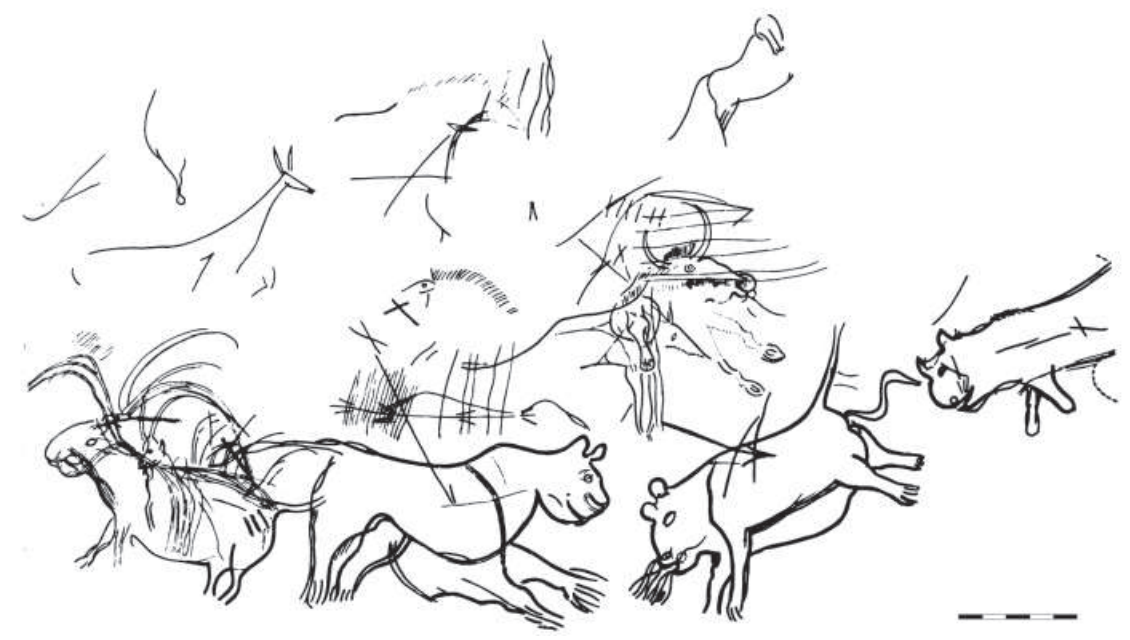


cific articulated body movements and postures, whether executed by an actor, expected to happen on the basis of immediately preceding perceptual history, or implied by the articulation of limbs in a static body posture [20].

Significantly, rhesus monkeys, when shown pictures of threatening monkey faces or pictures of monkey infants, exhibit responses-whether exploration, play, vocalization, or disturbance-that are appropriate to the situation [21]. They respond with hasty retreat, vocalizations and threat responses to the slides of threatening faces (and also display an abortive approach-retreat before touch- ing these images). However, these subjects quickly realized that the stimuli were unresponsive and immobile [22]. The interest of these reactions lies in the light that they may throw on the relation between the illusion of a picture that appears to become alive and human awareness.

We would not expect that rhesus macaques could comprehend deception in appearances. Images in fact aroused in them the same response as did real-life stimuli. This reaction is probably linked in part to an inappropriate MT and STS activation that "enlivens" the image. Indeed the leading edge of the propagat-

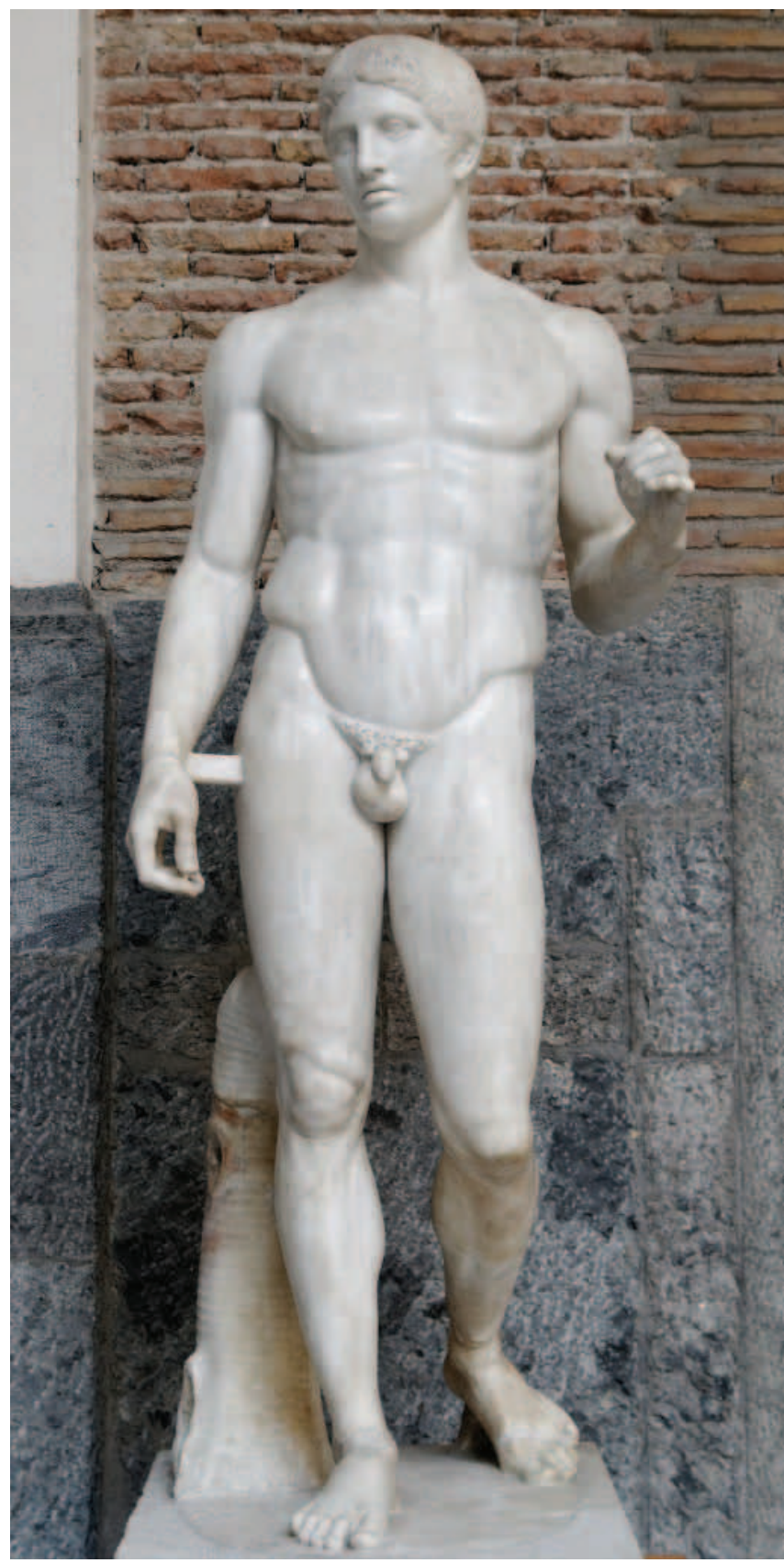

Fig. 3. Viewing the Doryphoros by Polykleitos, ca. 440 BCE, has been shown to activate motion areas in the brain. (Photo @ MarieLan Nguyen. Image source: <Wikipedia. org $>$. Creative Commons CC-BY.2.5/ deed.en License.) ing wave of neural activity triggered by motion-and probably by implied motion-onset and flowing from the retina into MT and beyond to other dorsal regions is ultimately sufficient to mediate a rapid behavioral response [23]. The responses that motivated the monkeys to react to the images as if to real beings may also be potentially present in us.

In everyday life, for a human being, activation of typical motion areas of the brain appears to be sufficient to convey motion. Zeki and ffytche emphasized the presence of crude visual awareness in patients with a lesion of the primary visual cortex (V1) [24]. They reported hMT+ activation, visual awareness and intact direction discrimination in patients' blind fields when exposed to moving vs. static stimuli. A patient described the motion as being approximately like "a black shadow moving on a black background" [25]. hMT+ is also engaged in processing implied dynamic information from static images and may be sufficient to bring images alive in the mind. Aspects of a vaguely anticipated motion probably also surface into conscious awareness.

\section{IMPLIED Motion, ATTENTION AND CONSGIOUSNESS}

In the human brain, this illusion of movement could be accessible to conscious probing: This is why we rarely confuse an image with the scene it represents. Unlike animals, humans are supposed to have privileged access to their own mental experiences.

Thus, in his experience in front of Michelangelo's Moses, which activates $\mathrm{hMT}+$, STS and many mirror areas [26], Sigmund Freud was torn between the feeling of motion suggested by the image and the consciousness of its immobility:

I can recollect my own disillusionment when ... I used to sit down in front of the statue in the expectation that I should now see how it would start up on its raised foot, dash the Tables of the Law to the ground and let fly its wrath. Nothing of the kind happened. Instead, the stone image became more and more transfixed . . . and I was obliged to realize that something was represented here that could stay without change; that this Moses would remain sitting like this in his wrath forever [27].

Freud so focused on the image that he forgot the material context. His attention was entirely image-based as he awaited the motion. Thus it seems that the feeling of motion is linked with attention.

Significantly, O'Craven et al. [28] found greater hMT+ activation when subjects attended to moving dots than when 


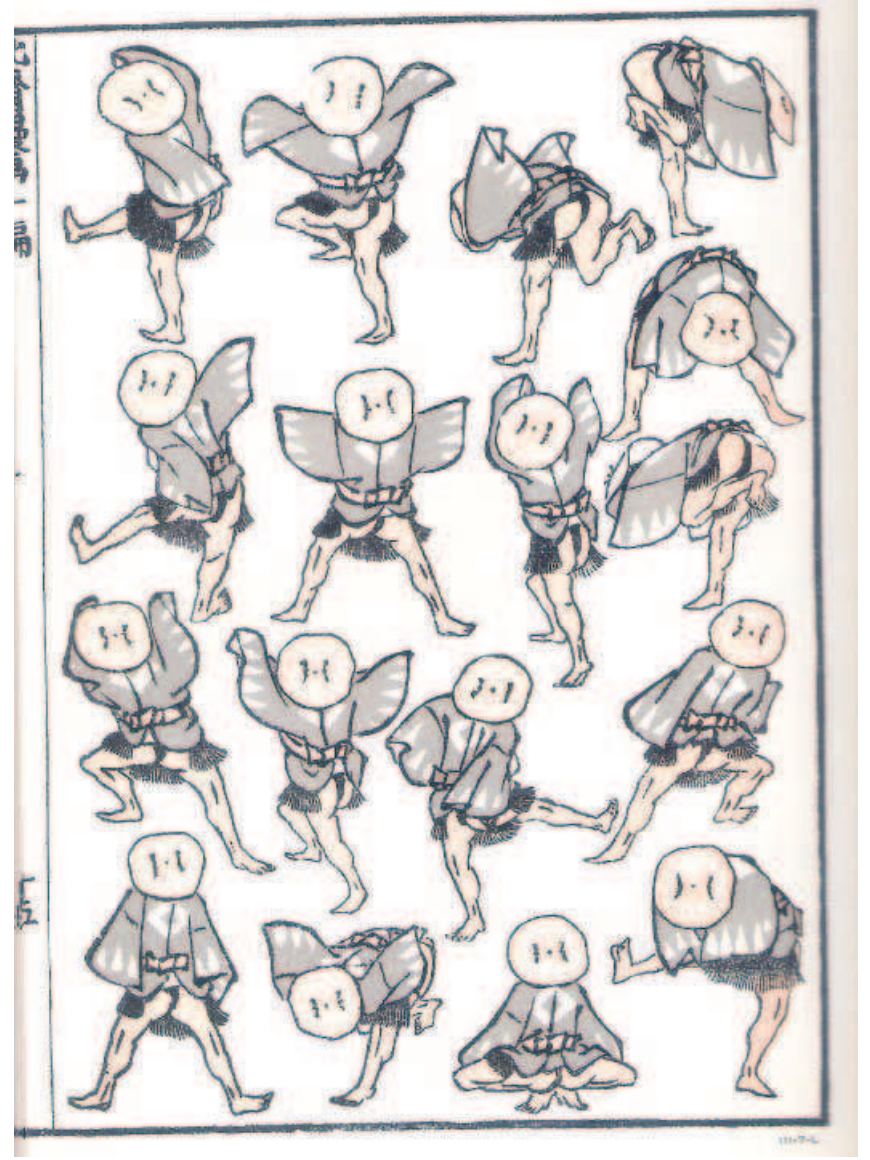

Fig. 4. Katsushika Hokusai, Suzume Udori-zu, pre-1849. The viewing of this drawing activates the motion-sensitive visual cortex, including MT+ in the human extrastriate cortex.

they attended to stationary dots, even though the visual stimulus remained unchanged. Images of beloved persons, dangerous animals or divinities are clearly evolutionarily (e.g. fear- or sex-) relevant stimuli. Humans have an attentional bias for such emotionally charged stimuli compared to emotionally neutral stimuli, such as flowers, and imagine emotionally charged images more easily as moving dots. With charged images, $\mathrm{hMT}+$ also should be more immediately active than when a subject views a less attractive stimulus. This would explain why, when one walks through the woods, the sight of a slender, curved shape lying flat on the path is sufficient to elicit a fearful response, as if it were a real and mobile snake, or why the image of a beloved or a dangerous creature is often imagined as becoming alive.

Additionally, the difference in extracranial potentials between responses to pictures with and without implied motion was maximal in the $\mathrm{hMT}+$ area between 260 and $400 \mathrm{~ms}$ after stimulus onset [29]. This area showed a response to real motion, but approximately 120 ms earlier than the implied motion response. This view is in agreement with nection with the content of myths and stories in which an image comes to life. There is a large body of research on the role played by hMT+, STS and premotor areas in the comprehension of action verbs and sentences. Osaka observed the activation of the human extrastriate visual cortex, including hMT+ and STS, on presentation of words that implied "walking," perceived by the ears while both eyes were closed [31]. Imagined motion of individuals engaged in activity also activates the hMT+ and STS areas [32]. Goebel et al. [33] reported activity in hMT+ when subjects imagined movement compared to when viewing stationary stimuli. Additionally, while reading about action in the context of a narrative, readers' specific motor areas that are also involved in performing, imagining or observing similar real-world activities are dynamically activated [34]. These features might provide a mechanism that explains how a perceptual activity can be translated into mythology.

We can suppose that activation of the hMT+, STS and mirror neuron areas by images with implied motion may facilitate their subsequent activation by sentences that also imply biological motion. This activation could also increase the credibility of these sentences and facilitate their memorization.

The neural response of the cortical region coding motion sentences should increase when an image with implied motion has been previously seen. Thus the experience of implied motion should produce an enhancement in hMT+, STS and the mirror neurons. For instance, Shulman et al. [35] presented a stationary arrow that either indicated the direction of motion in a subsequent motion-detection test or provided no directional information. The task then was to detect coherent motion in the test stimulus. In accordance with my hypothesis here, a stationary arrow cue specifying the direction of motion enhanced the BOLD signal during a motion detection task in both dorsal (e.g. anterior intraparietal sulcus) and ventral (e.g. left MT+) motion-sensitive regions, as well as motion-insensitive regions (e.g. posterior intraparietal sulcus). This enhancement was greater with a stimulus that indicated the direction of motion than with a stimulus that provided no directional information. The arrow cue produced modulations in motionsensitive regions before the onset of the test period in which moving stimuli were presented, indicating that these regions were involved in the encoding and/ or maintenance of directional instruc- 
tion signals to the detection of the test stimulus.

The activation of $\mathrm{hMT}+$, STS and mirror neuron areas by implied motion may increase the credibility of action sentences linked to these images. It may also facilitate their memorization. Regarding this latter prediction, moving images are remembered better than static ones [36]. This memorization factor is very important, because a tale not easily remembered arguably would not survive among competing tales in which images did not become alive.

Can this hypothesis be tested? Certainly, and I propose two experiments to test it. First, subjects would be shown images consisting of either impliedmotion images or non-implied motion images. Each image would be in black and white, either a painting or a photograph; it would remain on the screen for 4 seconds, after which the participant would rate its distinctiveness (on a scale from "very distinct" to "very indistinct") to ensure engagement with the stimuli. After each image was viewed, two sentences would be presented simultaneously for 4 seconds, the first describing an action with no relation to the content of the image (e.g. for a picture with a dancing human, "the animal runs"), the second describing inaction (e.g. "the animal sleeps"). For the subjects having seen an image with implied motion and subsequently read an action sentence, I predict that a greater signal change would be observed in the STS, hMT+ and mirror neuron areas than that caused by the reading of an action sentence alone.

In the second experiment, participants would study 100 implied-motion and 100 static images and paintings showing figures in black and white. The protocol would be the same as in the first experiment, except for the scan. Participants would return 1 week later for a test session during which they would read 100 old and 100 new sentences of each type and indicate whether or not they had read each sentence during training. They would return again a month after training for a second test session, identical to the first. None of the sentences shown in the first test would be used in the second. The results should demonstrate superior recognition memory for action sentences associated with implied motion images than for other action sentences or static sentences.

These two proposals show that my hypothesis is testable by empirical experiment and thus conforms to the standards of scientific method.
To conclude, neurobiology may easily explain the universal theme of animation. Implied motion may influence consciousness either directly, as the feeling of a sensation, or indirectly, by the preactivation of neuronal areas activated by both implied motion and myths.

\section{FROM THE MYTH TO THE BRAIN}

Language can certainly be used to evoke expectations and, therefore, illusions. Human beings can thus yield to suggestion through words. Extreme situations, such as suggestion under hypnosis, exemplify the power of words to mediate an illusion through anticipation.

Under these conditions, it is easy to assume that mythological themes may help human beings more easily perceive anticipated motion in an image. Many results (as in the section above) support the view that mythological understanding may stimulate and consequently prepare the motion areas of the brain that are necessary to anticipate such motion. Motion imagery and motion perception share the same direction-selective neural circuitry [37]; thus, even if myths are narrative works and not viewable events, they could have influenced the way in which we see objects.

If this is true, we can predict that hearing a short story in which an image becomes alive before seeing an image with implied motion will provoke a greater potential activation and greater BOLD activity in the brain motion area than viewing an implied-motion image that is not contextualized by a story. A similar increase should occur when the subject imagines that implied motion will really become live. To supplement our data, it would be necessary to test (1) whether a story that simply contains descriptions of motion and action increases the response to an implied-motion image; and (2) whether such a story would increase the response to a lesser extent than a story in which images come to life. A contradictory result would then mean that the critical factor lies in the motion, not in the coming to life.

Many study findings are consistent with this prediction. First, in a classical experiment using positron emission tomography (PET), subjects were asked to pay attention to different features of the same visual arrays (color, shape or speed of motion of the elements). The instruction to attend to a particular dimension (e.g. motion) enhanced responses in the extrastriate area coding that dimension (e.g. hMT+) [38]. Secondly, after read- ing a sentence describing an action, subjects were quicker to recognize a picture that is consistent with the action than a picture that is inconsistent with the action [39]. Similarly, participants who had heard a sentence describing a ball moving forwards or backwards (e.g. "The pitcher hurled the softball toward you") and had successively seen two images depicting a ball responded more quickly when the implied movement of the balls matched the movement described in the sentence [40].

These results provide strong support for the view that (1) myth comprehension involves dynamic perceptual simulations of motion and (2) hearing a story in which an image becomes alive activates the motion areas of the brain, as does viewing an image with implied motion, and can prepare and increase brain activation by the actual viewing of an image.

\section{Conclusion}

These results alone cannot resolve the question of the relationship between art and myths or the origin of mythological universals. These are far too complex. Recent data can only explain one of the numerous fictional themes common to all continents-the image that comes to life. However, I hope that these data will serve as a starting point and impetus to future research in this area.

\section{Acknowledgments}

The author thanks Jean Decety, Derek Hodgson, Jean-Loïc Le Quellec, Jeannette A.M. Lorteije, Lionel Naccache, Leonard Talmy, Thomas Wynn and the anonymous Leonardo reviewers for helpful discussions and comments. Special thanks to Ariela Sillam, Marie Heraud, Hélène Huguet and Béatrice Rossi-Bouchera.

\section{References and Notes}

Unedited references as provided by the author.

1. J. d'Huy, "Le thème mythique de l'image qui s'anime aurait un fondement neurologique et remonterait à la Préhistoire," Les Cahiers de l'AARS No. 14, 73-84 (2011).

2. J. d'Huy, "New evidence for a closeness between the Abu Râ's shelter (Eastern Sahara) and Egyptian beliefs," Sahara No. 20, 125-126 (2009); J. d'Huy and J.L. Le Quellec, "Du Sahara au Nil: la faible représentation d'animaux dangereux dans l'art rupestre du Sahara oriental pourrait être liée à la crainte de leur animation," Les Cahiers de l'AARS No. 13, 85-98 (2009); J. d'Huy and J.L. Le Quellec, "Les animaux 'fléchés' à Lascaux: nouvelle proposition d'interprétation," Préhistoire du Sud-Ouest Vol. 18, No. 2, 161-170 (2010); J. d'Huy and J.L. Le Quellec, "Les Ihizi: et si un mythe basque remontait à la préhistoire?” Mythologie française No. 246, 64-67 (2012).

3. P. Descola, ed., La Fabrique des Images: Visions du Monde et Formes de la Représentation (Paris: Somogy/ Musée du quai Branly, 2010).

4. J.E. Cutting, "Representing motion in a static 
image: Constraints and parallels in art, science, and popular culture," Perception No. 31, 1165-1193 (2002)

5. J. Freyd, "Representing the dynamics of a static form," Memory and Cognition Vol. 11, No. 4, 342-346 (1983); Futterweit and Beilin have corroborated this effect in children: L.R. Futterweit, H. Beilin, "Recognition memory for movement in photographs: A developmental study," Journal of Experimental Child Psychology Vol. 57, No. 2, 163-179 (1994).

6. Z. Kourtzi, N. Kanwisher, "Activation in Human MT/MST by Static Images with Implied Motion," Journal of Cognitive Neuroscience Vol. 12, No. 1, 48-55 (2000); C. Senior et al., "The Functional Neuroanatomy of Implicit Motion Perception or 'Representational Momentum," Current Biology Vol. 10, No. 1, 16-22 (2000)

7. C. Di Dio, E. Macaluso, G. Rizzolatti, "The Golden Beauty: Brain Response to Classical and Renaissance Sculptures," PLoS ONE Vol. 2, No. 11: e1201 (2007).

8. J.A.M. Lorteije et al., "Delayed Response to Animate Implied Motion in Human Motion Processing Areas," Journal of Cognitive Neuroscience Vol. 18, No. 2, 158-168 (2006).

9. J.A.M. Lorteije et al., "Adaptation to Real Motion Reveals Direction-Selective Interactions between Real and Implied Motion Processing," Journal of Cognitive Neuroscience Vol. 19, No. 8, 1231-1240 (2007).

10. N. Osaka et al., "Implied motion because of instability in Hokusai Manga activates the human motion-sensitive extrastriate visual cortex: An fMRI study of the impact of visual art," NeuroReport No. 21, 264-267 (2010).

11. T. Allison, A. Puce, G. McCarthy, "Social Perception from Visual Cues: Role of the STS Region," Trends in Cognitive Sciences, Vol. 4, 267-278 (2000).

12. M.A. Amorim et al., "Modulation of Spatial Orientation Processing by Mental Imagery Instructions: A MEG Study of Representational Momentum," Journal of Cognitive Neuroscience Vol. 12, No. 4, 569-582 (2000); I.P. Fawcett, A. Hillebrand, K.D. Singh, "The Temporal Sequence of Evoked and Induced Cortical Responses to Implied-Motion Processing in Human Motion Area V5/MT+," European Journal of Neuroscience Vol. 26, No. 3, 775-783 (2007); Kourtzi and Kanwisher [6]; Senior et al. [6].

13. Osaka et al. [10].

14. T. Jellama, D.I. Perrette, "Cells in Monkey STS Responsive to Articulated Body Motions and Consequent Static Posture: A Case of Implied Motion?,' Neuropsychologia Vol. 41, 1728-1737 (2003); "Neural Representations of Perceived Bodily Actions using a Categorical Frame of Reference," Neuropsychologia Vol. 44, No. 9, 1535-1546 (2006); Allison et al. [11].

15. According to "simulation theory"; see V. Gallese and A. Goldman, "Mirror neurons and the simulation theory of mind-reading," Trends in Cognitive Sciences No. 2 (12), 1998, 494-501.

16. Di Dio et al. [7].

17. A.M. Proverbio, F. Riva, A. Zani, "Observation of Static Pictures of Dynamic Actions Enhances the Activity of Movement-Related Brain Areas," PLoS ONE 4(5): e5389 (2009)
18. Osaka et al. [10].

19. B. Krekelberg, A. Vatakis, Z. Kourtzi, "Implied motion from form in the human visual cortex," Journal of Neurophysiology No. 94, 4376-4386 (2005).

20. Jellama and Perrette [14].

21. G.P. Sackett, "Monkeys reared in isolation with pictures as visual inputs: Evidence for an innate releasing mechanism," Science, Vol. 154, 1468-1472 (1966).

22. S.A. Rosenfeld, G.W. Van Hoesen, "Face recognition in the rhesus monkey," Neuropsychologia 17 , 503-509 (1979)

23. E.P. Cook, J.H.R. Maunsell, "Dynamics of neuronal responses in macaque MT and VIP during motion detection," Nature Neuroscience Vol. 5, No. 10, 985-994 (2002)

24. S. Zeki, D.H. ffytche, "The Riddoch syndrome: Insights into the neurobiology of conscious vision," Brain, No. 121, 25-45, 1998; S. Zeki, D.H. ffytche, "The primary visual cortex, and feedback to it, are not necessary for conscious vision," Brain Vol. 134, No. 1, 247-257 (2010).

25. Zeki and ffytche [24]

26. Di Dio et al. [7]

27. S. Freud, Writings on art and literature (Stanford University Press, 1997) p. 132

28. K.M. O'Craven et al., "Voluntary attention modulates fMRI activity in human MT-MST," Neuron No. 18, 591-598 (1997)

29. Lorteije et al. [8]

30. Senior et al. [6].

31. N. Osaka, "Walk-related mimic word activates the extrastriate visual cortex in the human brain: An fMRI study," Behavioral Brain Research No. 198, 186-189 (2009).

32. E.D. Grossman, R. Blake, "Brain activity evoked by Inverted and Imagined Biological Motion," Vision Research Vol. 41, 1475-1482 (2001).

33. R. Goebel et al., "The constructive nature of vision: Direct evidence from functional magnetic resonance imaging studies of apparent motion and motion imagery," European Journal of Neuroscience Vol. 10, No. 5, 1563-1573 (1998).

34. N.K. Speer et al., "Reading stories activates neural representations of visual and motor experiences," Psychological Science Vol. 20, No. 8, 989-999 (2009).

35. G.L. Shulman et al., "Areas involved in encoding and applying directional expectations to moving objects," The Journal of Neuroscience Vol. 19, No. 21, 9480-9496 (1999).

36. W.J. Matthews, C. Benjamin, C. Osborne, "Memory for moving and static images," Psychonomic Bulletin and Review Vol. 14 No. 5, 989-993 (2007).

37. J. Winawer, A.C. Huk, L. Boroditsky, "A motion aftereffect from visual imagery of motion," Cognition Vol. 114, 276-284 (2010)

38. K.M. O'Craven, P.E. Downing, N. Kanwisher, "fMRI evidence for objects as the units of attentional selection," Nature No. 401, 584-587 (1999).
39. R.A. Zwaan, R.A. Stanfield, R.H. Yaxley, "Language comprehenders mentally represent the shape of objects," Psychological Science Vol. 13, 168-171 (2002)

40. R.A. Zwaan et al., "Moving words: Dynamic representations in language comprehension," Cognitive Science Vol. 28, No. 4, 611-619 (2004).

\section{Glossary}

blind field-people who are perceptually blind in a certain area of their visual field demonstrate some response to visual stimuli.

BOLD-blood-oxygen-level dependence: the MRI counterpart of blood deoxyhemoglobin. Changes in BOLD signals are well correlated with changes in blood flow.

EEG-electroencephalography, recording of electrical activity along the scalp.

extrastriate area-region of the occipital cortex that encompasses multiple functional areas, including V3, V4, V5/hMT+ and the extrastriate body area.

fMRI-functional Magnetic Resonance Imaging procedure that measures brain activity by detecting associated changes in blood flow.

Glass sequences-arrangements of dots suggesting a path of motion.

implied motion-the suggestion of motion in a stationary object.

mirror neurons-neurons that fire both when an animal acts and when the animal observes the same action performed by another.

hMT+_human Middle Temporal complex; see MT.

MT-Middle Temporal complex, a region of the extrastriate visual cortex that is thought to play a major role in the perception of motion.

representational momentum-small error in our visual perception of moving objects. Instead of knowing the exact location of a moving object, we actually think it is a bit further along its trajectory.

STS-Superior Temporal Sulcus: a region of the temporal lobe of the brain that is involved in the perception of biological motion.

V1-primary visual cortex, the simplest, earliest cortical visual area.

Manuscript received 26 July 2011.

Julien d'Huy is a Ph.D. student in anthropology who explores new ways (e.g. phylogenetic, neurobiological) of understanding shared themes and characteristics of myths from diverse cultures. 